EPiC Series in Education Science
Volume 1, 2017, Pages 227-234
$\begin{aligned} & \text { AUBEA 2017: Australasian Universities Build- } \\ & \text { ing Education Association Conference 2017 }\end{aligned}$

\title{
Identifying Barriers to Retaining Female Professionals in Engineering and Construction Organisations
}

\author{
$\underline{\text { N. Naismith }}^{1}$, S. Robertson ${ }^{2}$, J. Tookey, \\ ${ }^{1}$ Senior Lecturer, Auckland University of Technology \\ ${ }^{2}$ Senior Project Manager, ARUP \\ nicola.naismith@aut.ac.nz
}

\begin{abstract}
The construction and engineering industry remains to be one of the most male dominated industries in the world, with between 10 and 25 percent of its employees being female. It is believed that only $62 \%$ of women who pursued engineering stayed within the industry. Research suggests that the biggest hurdle the industry needs to overcome is changing the culture within the industry. For engineering and construction organisations gender diversity adds to the opportunity to engage a more diverse range of skills and ideas, with gender diverse organisations being 15\% more likely to outperform their respective industry median. It also enables organisations to match the projected more gender diverse client teams and reflect the stakeholders in the communities they serve. The aim of the study is to provide a better understanding of how do we attract and retain female professionals within the construction industry and ensure gender diversity within senior leadership teams. An exploratory qualitative study was conducted with 3 females and 1 male working within the construction and engineering industry. The results suggest that the majority of interviewees joined the construction industry due to the encouragement of a family member and all agreed that having a gender diverse team was important as it creates for more diverse communication with the clients and stakeholders. However the difficult workplace culture and stereo typing still exists particularly around the need to have to work long hours which creates difficulties when trying to balance family and career.
\end{abstract}

Keywords: Construction Industry, Employee Retention, Engineering Industry, Gender Diversity. 


\section{Introduction}

Hunt et al (2015), shows that gender-diverse companies are 15\% more likely to outperform their respective industry medians. It is also seen that companies that can attract and retain this form of diversity, have a more competitive advantage. Shoellkopf (2014), outlines that "Fortune 500 companies with at least three female directors have seen their return on invested capital increase by at least $66 \%$, return on sales increase by $42 \%$, and return on equity increase by at least $53 \%$ ".

The US Department of Labour (DOL) identifies an occupation as being a "non-traditional" occupation when women comprise of less than $25 \%$ of its workforce. As of 2008, (DOL, 2009) and outlined by Sewalk et al (2015), women accounted for $8.2 \%$ of construction managers and for $3.3 \%$ of the construction workforce, making it "non-traditional". Results are also similar for related industries such as architecture, for which women make up $24.8 \%$, for engineering technicians which women make up $18.5 \%$, for industrial engineers which are made up of $14.9 \%$ of women and for civil engineers which are made up of $10.4 \%$ of women. It is outlined that the gender distribution disparity in construction emerges at the initial stages, such as university entry level With an average of only $7.8 \%$ of female students choosing to go into construction management and women continue to be underrepresented in science, technology, engineering, and mathematics (STEM) fields (Bigelow et al, 2015). These demographics are pushing companies to look outside of recruiting only men and to consider how they would attract more women into the industry (Clarke and Gribling, 2008).

The ability to predict and develop policies and programmes and environments that enhance worklife balance and promote organisational commitment is important to minimising employee turnover (Malone et al, 2013) and to help attract and retain female engineers. However the belief is that the engineering industry is a competitive and conflictual environment, "where women are overtly and covertly discriminated against by men who use structural systems to undermine their participation" (Dainty et al, 1999, pg 239).

The construction industry does not attract significant numbers of women to its labour force. However, due to potential expected growth in the field, construction companies will need more women to meet their labour needs, (Sewalk et al, 2015).There is a need to understand how do we attract and retain more female professionals within the construction industry and ensure gender diversity within senior leadership teams.

\section{Literature Review}

A range of reasons have been suggested for the lack of women entering and staying in the construction industry. Sewalk et al (2015) suggests that many women feel like outcasts, unwelcome within the industry. Dainty et al (2000), conducted a study which showed that recruitment was routinely done by informal and personal sources, putting women at a disadvantage. As per Sewalk (2015, pg 242 ), "the man's way of doing business is deeply ingrained in the construction industry and many current male workers and owners of construction companies are very reluctant to change their existing hierarchies and work practices." Another point raised by Sewalk et al (2015), was that a great barrier was that of work-life balance for women within the industry and women were discouraged from working in construction if they wanted to have a family in the future, as maternity leave or other parental leave is not accepted within the industry. In addition, it was apparent that extended working hours (Dainty et al, 2000), failure to get equal opportunities and promotions (Hurley et al, 1999) lack of salary increases (Wilkinson, 1992) and sexual harassment (Fielden et al, 2000) were also barriers that were evident. 
Findings from Fouad (2014) concluded that only $62 \%$ of women who pursued engineering, stayed within the industry, $11 \%$ of these women never entered the field and $27 \%$ ended up leaving the industry. Amongst the women who left, two-thirds said they pursued better opportunities in other industries, and the other third stayed home because they felt companies didn't accommodate work-life concerns. From the women who left to go to other industries, $54 \%$ of these women went on to become executives. That women are seven to eight times more likely to attract unwanted sexual attention and $42 \%$ of cases leads to unexplained resignations of the victims. A study by Dorsey and Minkarah (1992) found that $37 \%$ of female respondents in their study were thinking about leaving their jobs because of mistreatment. Watts, (2007) and Sewalk et al (2015) suggest that the culture of the industry with its light hearted sexist joking and more subtle masculine behaviour may undermine female colleagues.

Sewalk et al (2015), suggests that lack of training, lower pay and career progression are also barriers to retaining women within the industry. Women are more likely than men, to leave the industry within the first 10 years of their careers (Dainty, 2000). This is hugely due to slow career progression and a "disillusionment with the culture," (Sewalk, 2015, pg 241). Perreault (1992), suggests that men continue to assume that women are not capable of performing the work required within the industry. Nor are they able to manage male employees or balance work and life commitments.

Sewalk et al (2015), discusses the study undertaken by Moore (2006), who suggested that the biggest single barrier for career development was finding a balance between personal and professional lives. Menches and Abraham (2007), also confirms that family matters strongly influences women's career paths. In a survey by Fielden et al (2001), of men and women, it was concluded that all participants felt that flexible working hours and access to childcare would increase the opportunities for women in the construction industry. Dainty et al (2000) identified that women in their 20 s and 30 s found it difficult to gain entry into the industry as managers were conscious of the potential responsibility women would have to face regarding their families in the future. Women therefore felt penalised for wanting to have families as they were seen as unreliable if they required time off work. A common perception became that women felt they needed to choose between a career and having a family and that it wasn't possible to have both.

Institution of Professional Engineers New Zealand (IPENZ) have also conducted research into these issues investigating barriers to women remaining and progressing in the engineering industry. Their report Women in Engineering: Preliminary Report on WIE Survey (2008) and further discussed by Ayre (2011) determined that workplace culture strongly influenced female engineers. It showed that $21 \%$ of female engineers had reported being sexually harassed, 39\% reported having experienced gender discrimination and $25 \%$ had reported having experienced bullying. An interview with Tracey Ayre (2014), concluded that stereotyping and workplace culture, particularly around the need to have to work long hours, the lack of visible role models and the lack of transparency in pay, were all key reasons for women leaving the industry.

The literature review reveals a number of themes for consideration. There are significant benefits to having a more gender balanced workplace; there are a range of barriers that exist to attracting females into the industry and retaining them in the industry. Research indicated that the biggest hurdle the industry needs to overcome, is changing the culture so that males accept their female counterparts as equals. As suggested by Dainty (2000), rather than just recruiting more women into the industry, the focus should be on changing the culture within the industry.

\section{Research Method}

The purpose of the study was to gain a better understanding of how do we attract and retain female professionals within the construction industry and ensure gender diversity within senior 
leadership teams. The nature of the research aim required an inductive approach to be taken as this is more open ended and exploratory in nature and would enable initial findings to emerge from the construction context. Qualitative research was selected as a methodology as it is ideal for establishing perspectives and answering the 'how' and 'why', this was appropriate given the complex nature of the construction industry and its lack of women being represented.

The data collection method of face to face semi structured interviews was chosen as it is well suited for the exploration of perceptions regarding complex and sensitive issues (Barriball and White 1994). The interviews incorporated both open-ended and more theoretically driven questions which helped to draw interviewees more effectively into the topic under study (Galletta and Cross, 2013). The semi structured interview schedule was developed based on the key themes from the literature including the benefits of gender diversity, lack of women entering the industry and their subsequent progression and retention.

In terms of sample size, qualitative research focuses on exclusivity of text and possibility of different interpretations from the data, the size of the sample is limited (Marsh and White, 2006). They further stated that the focus of research should be transferability rather than generalizability per se. For the purpose of this exploratory study, a homogeneous sampling method was adopted (Patton, 1990). This method involves selecting a small homogeneous group of construction industry professionals (unit of analysis) for examination.

As the research was exploratory in nature the sample selection process involved selecting 4 individuals at varying stages of their careers with the intention that their experience would provide rich data. High achieving individuals were chosen through network connections. To ensure that these people were taking all steps possible to progress their careers, with aspirations of leadership roles within their current or near future.

Table 1 outlines the interviewees' demographic profiles, indicating their gender, age, family status, breadth and depth of industry experience in the construction industry.

\section{Table 1: Interviewees' Demographic Profiles}

\begin{tabular}{|l|l|l|l|l|l|}
\hline Interviewee & Gender & Age & $\begin{array}{l}\text { Family } \\
\text { Status }\end{array}$ & $\begin{array}{l}\text { Job Role/ } \\
\text { Organisation } \\
\text { Type }\end{array}$ & $\begin{array}{l}\text { Length of professional } \\
\text { experience }\end{array}$ \\
\hline 1 & Female & $20-24$ & $\begin{array}{l}\text { No } \\
\text { Children }\end{array}$ & $\begin{array}{l}\text { Professional } \\
\text { engineer, in a } \\
\text { junior to } \\
\text { intermediate level } \\
\text { role }\end{array}$ & $\begin{array}{l}\text { Within the first 5 years of } \\
\text { their career }\end{array}$ \\
\hline 2 & Female & $25-34$ & $\begin{array}{l}\text { No } \\
\text { Children }\end{array}$ & $\begin{array}{l}\text { Professional, non- } \\
\text { engineer, in an } \\
\text { intermediate to } \\
\text { senior level role }\end{array}$ & $\begin{array}{l}\text { Within the first 10 years of } \\
\text { their career }\end{array}$ \\
\hline 3 & Male & $25-34$ & $\begin{array}{l}\text { Has } \\
\text { Children }\end{array}$ & $\begin{array}{l}\text { Professional } \\
\text { engineer, in an } \\
\text { intermediate to } \\
\text { senior level role }\end{array}$ & $\begin{array}{l}\text { Within the first 10 years of } \\
\text { their career }\end{array}$ \\
\hline 4 & Female & $35-44$ & $\begin{array}{l}\text { Has } \\
\text { Children }\end{array}$ & $\begin{array}{l}\text { Professional } \\
\text { engineer, senior } \\
\text { level role }\end{array}$ & $\begin{array}{l}\text { 10 years plus work } \\
\text { experience }\end{array}$ \\
\hline
\end{tabular}


Content analysis was used to analyse the data as it allows for data interpretation and making inferences for identifying the key message conveyed (Stemler, 2001). It also allows the researcher to make for making valid inferences from the data to their context, helping to provide knowledge, and new insights (Krippendorff, 1980; Elo and Kynga, 2008). This approach meant that the data collected was rich and in depth. The themes that emerged from the data are now presented.

\section{Results and Discussion}

Three main themes emerge from the data for discussion including reasons for entering the industry, the need for gender diversity in the construction industry and issues around entry, progression and retention of women.

\section{Entering the industry}

The interviewees were asked to explain their reasons for joining the construction industry as a career. The majority of interviewees joined the construction industry due to the encouragement of a family member. Three of the interviewees had a male role model of a father or uncle in the industry. Interviewee 1 stated 'Father was an engineer and I would not have gone into it if not for him'. Interviewee 3 highlighted that one of the reasons for him choosing to go into the industry was due to his interest in the STEM subjects. This finding supports the work of Sewalk et al (2015) who stated that unless parents were involved within the industry, young girls were not attracted to it.

\section{The need for gender diversity}

All participants felt that there is a gender gap issue within the industry. Interviewee 1 explained 'Yes. There is a gap from the university level already. With this growing as it heads into senior leadership positions. 'Two of the interviewees went on to explain that this gender gap has implications for professional women in the industry including '...feeling unwelcome within the industry. You question your own abilities. Feel less respected, (Interviewee 2). To the need to work long, excessive hours, in order to prove themselves. In most cases feeling it is required to work harder than men in order to be perceived as being on par with them.

All participants agreed that having a gender diverse team was important, noting that it creates for more diverse communication with the clients and stakeholders. Interviewee 3 confirmed that 'Yes... Makes for a more interesting group of people to work with and outcomes are improved. Allows for a greater range of perspectives.'

The interviewees felt that women bring a range of positive attributes to the workplace including empathy, sensitivity and a strong teamwork focus. However all of the female interviewees felt that the need to play down their feminine identity to try and fit in to the industry .Interviewee 1 explained '...Pressure to have a lot of physical hobbies to try and fit in with male counterparts. If you talk about female things, your perceived IQ levels drop'.

\section{Entry, progression and retention of women in the industry}

The interviewees were asked to discuss their perceptions concerning the lack of entry of women into the construction industry as well as the causes for women to leave the industry. A key fact that was outlined by the interviewees, was that girls are not encouraged to enter into STEM subjects at a young age and is a strong factor as to why they do not choose engineering as an option at university level. 
'Biggest barrier to entry would be at university entrance level. Perceptions of industry being too male dominated' (Interviewee 3 ). This therefore creates that gender gap at an early stage.

The interviewees confirmed that it is still a male dominated industry and therefore women feel discouraged to enter. Interviewee 2 offered a range of reasons including 'Very male dominated. Hard to reach leadership positions. Hard to balance family and career.' This confirms the work of Ayre (2014) who concluded that stereotyping and workplace culture don exist, particularly around the need to have to work long hours.

Perceived reasons for leaving the industry included better opportunities in other industries but most focused on the issues concerning the challenges of balancing work and life 'particularly if raising children' (Interviewee 3) and Interviewee 4 who stated 'Women tend to want to leave to have a family and find transitioning back difficult.' This supports the findings of Fouad (2014) who confirmed that two-thirds of women who left the industry pursued better opportunities in other industries, and the other third stayed home because they felt companies didn't accommodate work-life concerns.

In terms of the barriers that exist to personal career progression interviewee 2 and 4 focussed on the issue of the long working hours 'Women have to work harder/ longer hours to prove themselves especially on site.' Whereas Interviewee 3 stated that 'White males are progressed ahead of others because of their perceived leadership potential.' Interviewee 1 outlined the lack of mentorship available in the industry as a barrier as well as the lack of acceptance by men stating that 'When women are friendly with male colleagues, they are seen as flirty. Males find it hard to accept them into their social circle.' Twenty years later this supports the work of Watts (2007) who outlines, subtle masculine behaviour is used to undermine female colleagues.

Participants felt that maternity leave or working part time did prove to be a setback in terms of their progression opportunities. Interviewee 2 felt that think 'maternity leave would definitely affect career progression. You have to be "seen" to progress. Don't usually pick up where you left off.... Fall behind.' Interviewee 4 had direct experience of maternity leave affecting their career progression stating that 'This has slowed down my career progression. It is hard to work part time hours as you tend to do a lot of over time. It is easier if your husband has more flexibility around their job. Pay gap following maternity leave.' Interviewee 2 felt afraid to even bring up the prospect of having a family as she feels she would be discriminated against and automatically overlooked for senior roles due to the perception that she would choose family obligations over those of her professional commitments. This supports the work of Dainty et al (2000) who outlined that managers are conscious of the potential responsibility that women could face if choosing to have a family, thus penalising them before they've even made the decision.

\section{Conclusions}

The aim of the study was to provide a better understanding of how we attract and retain female professionals within the construction industry and ensure gender diversity within senior leadership teams. The results of this exploratory qualitative study suggests that women remain to be underrepresented within the industry. Although there continues to be some growth over the years, it is not enough to sustain labour demands or meet the changing demands of the clients and the greater environment and social requirements.

The study confirms that female professionals joined the construction industry due to the encouragement of a family member rather than the attractive nature of the industry to young people. There is a requirement to attract more female professionals into the industry and having a gender diverse team is important as it creates for more diverse communication with the clients and stakeholders. The difficult workplace culture and stereo typing still exists and undermines women in the workplace. There are issues concerning the need to have to work long hours which creates difficulties when trying to 
balance family and career. People felt that maternity leave or working part time was a setback in terms of their progression opportunities.

These results provide examples that the industry has not progressed as far as it would have liked in the last 20 years in terms of diversity, however due to the pilot nature of the study more research is needed in this area. Further research could help to unpack these issues in more detail and to allow these initial findings to be verified. Further research in this area is currently taking place as part of a three year project to examine the issues generated from this study as part of a current larger qualitative study examining women's career paths in the construction industry in New Zealand.

\section{References}

Ayre, T. (2011). 'Barriers to Women Remaining and Advancing in the Engineering Profession'. Report to the IPENZ Women in Engineering Oversight Body. Retrieved from https://ipenzproduction.blob.core.windows.net/cms-library/docs/default-source/newspublication/Diversity/2011 barriers-remaining-advancing.pdf?sfvrsn $=4$

Ayre, T. (2014). 'Why Women Shun Engineering as a Career' (2014). Retrieved March 25, 2016 from https://www.westpac.co.nz/rednews/women/why-women-shun-engineering-as-a-career-newresearch/

Barriball, L. K., White, A. (1994). Collecting Data using a semi-structured interview: a discussion paper. Journal of Advanced Nursing, Vol. 19 (2), pp. 328-335.

Bigelow, B.F., Bilbo, D., Mathew, M., Ritter, L., Elliott, J. W., Identifying the Most Effective Factors in Attracting Female Undergraduate Students to Construction Management, International Journal of Construction Education and Research Vol. 11, (3), 2015.

Clarke, L., Gribling, M. (2008). Obstacles to diversity in construction: the example of Heathrow Terminal 5. Construction Management and Economics (2008) Vol. 26 (10), pp. 1055-1065.

Dainty, A.R., Bagilhole, B.M., and Neale, R.H. (1999). A Grounded Theory of Women's Career Underachievement in Large UK Construction Companies. Construction Management and Economics (2000) Vol. 18 (2), pp. 239-250.

Dainty, A. R., Bagilhole, B. M., and Neale, R. H. (2000). A grounded theory of women's career under achievement in large UK construction companies. Construction Management and Economics, Vol. 18 (2), pp. 239-250.

DOL (2009). Nontraditional occupations for women in 2008. Washington DC: Bureau of Labor Statistics, U.S. Department of Labor.

Dorsey, R.W., Minkarah, E. (1992) Women in Construction. Bureau of Engineering Research, Construction Industry Institute, University of Texas, Austin.

Elo, S., Kynga, S.H., (2008) The qualitative content analysis process. Journal of Advanced Nursing, 62 (1), pp. 107-115, doi: 10.1111/j.1365-2648.2007.04569.

Fielden, S. L., Davidson, M. J., Gale, A., Davey, C. L. (2001). Women, equality and construction. Journal of Management Development, Vol. 20 (4), pp. 293-304.

Galletta, A., Cross, W. E. (2013). Mastering the Semi-Structured Interview and Beyond: From Research Design to Analysis and Publication. NYU Press, New York. 
Hurley, A., Giannantonio, C. (1999). Career attainment for women and minorities: The interactive effects of age, gender and race. Women in Management Review, Vol. 14 (1), pp. 4-13.

Hunt, V., Layton, D., Prince, S. (2015) Why Diversity Matters. McKinsey \& Company. Retrieved from http://www.mckinsey.com/business-functions/organization/our-insights/why-diversity-matters

Krippendorff, K. (1980) Content Analysis: An Introduction to its Methodology. Sage Publications, Newbury Park.

Menches, C. L., Abraham, D. M. (2007). Women in construction-tapping the untapped resource to meet future demands. Journal of Construction Engineering and Management, American Society of Civil Engineers, Vol. 133 (9), pp. 701-707.

Moore, J. D. (2006). Women in construction management: Creating a theory of career choice and development. Fort Collins, CO: Dissertation, Colorado State University.

Malone, E., Issa, R., (2014). Predictive Models for Work-Life Balance and Organisational Commitment of Women in the U.S. Construction Industry. Journal of Construction Engineering

Management, Vol 14, (3), http://dx.doi.org/10.1061/(ASCE)CO.1943-

7862.0000809\#sthash.GQ0XMiFl.dpuf.

Patton, M. Q. (1990). Qualitative evaluation and research methods. Newbury Park, California: Sage Publications.

Perreault, R. (1992). Identification of the issues facing women in the construction industry and their relative importance. Proceedings of the Associated Schools of Construction $28^{\text {th }}$ Annual Conference, April 9-11, 1992, pp. 129-136.

Sewalk, S., Nietfeld, K. (2015). Barriers Preventing Women from Enrolling in Construction Management Programs. International Journal of Construction Education and Research, Vol. 9 (4), pp. 239-255, DOI: 10.1080/15578771.2013.76436

Shoellkopf, K. (2014). Hire More Women in Tech. A Few Simple Things You Can Do To Find And Hire More Qualified Women In Tech. Retrieved from http://www.hiremorewomenintech.com/

Stemler, S. (2001). An Overview of Content Analysis. Practical Assessment, Research \& Evaluation, Vol. 7 (17). Retrieved Aug 10, 2015, from http://pareonline.net/getvn.asp?v=7\&n=17

Watts, J. H. (2007). Porn, pride, and pessimism: Experiences of women working in professional construction roles. Work Employment and Society, Vol. 21 (2), pp. 299-316.

Wilkinson, S. (1992). Career paths and childcare: Employer's attitude towards women in construction. Proceedings from the Women in Construction Conference, 8th September, 1992, University of Northumbria. 